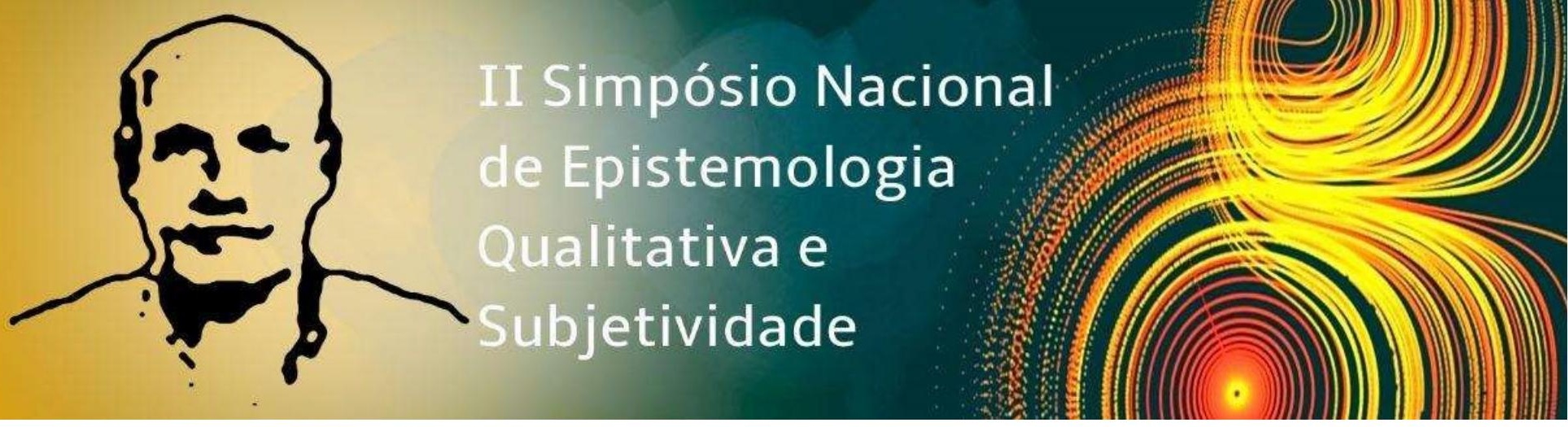

Eixo temático: Epistemologia Qualitativa e metodologia construtivo-interpretativa: discussões conceituais e relações com outras perspectivas epistemológicas e metodológicas

\title{
Subjetividade, docência e políticas públicas da educação infantil ${ }^{1}$
}

Luciana Oliveira Lemes, IP/Unb, luciana.lemes@gmail.com Carol Velho, Cultura, Educação e Infâncias - CEI, carolvelho@gmail.com

\section{Resumo}

A Política Nacional de Educação Infantil no Brasil se constituiu a partir de lutas e disputas, principalmente, no que diz respeito à identidade da Educação Infantil e ao entendimento acerca de seu funcionamento, da sua organização, do seu currículo. A partir dessa perspectiva técnica, muitas vezes, deixou-se de considerar o grupo de pessoas, gestores, coordenadores e professores, que efetivamente traduzem as políticas em ações cotidianas (VELHO, 2016). O estudo apoia-se na Teoria da Subjetividade em perspectiva cultural-histórica, de González Rey (2002; 2016; 2017). A partir dessa compreensão teórica aprofundam-se diálogos em que se procura evidenciar os sujeitos participantes da política municipal de educação e a complexa teia de ações, relações, sentidos, sentimentos desta equipe, que se implicam nas decisões sobre o desenvolvimento desta etapa educacional. O objetivo geral é compreender como os docentes subjetivam as suas ações no processo de desenvolvimento das políticas públicas da educação infantil do município. A pesquisa será realizada do $2^{\circ}$ semestre $/ 2019$ ao $1^{\circ}$ semestre/2021, no

\footnotetext{
${ }^{1}$ Esse estudo é parte de uma pesquisa intitulada: Understanding educational complexities: on equitable and transformative teaching and learning processes in a municipal system of early childhood education, aprovada em abril/2019, por meio de edital da Fundação Lemann em parceria com a Teachers College/ Columbia University.
} 


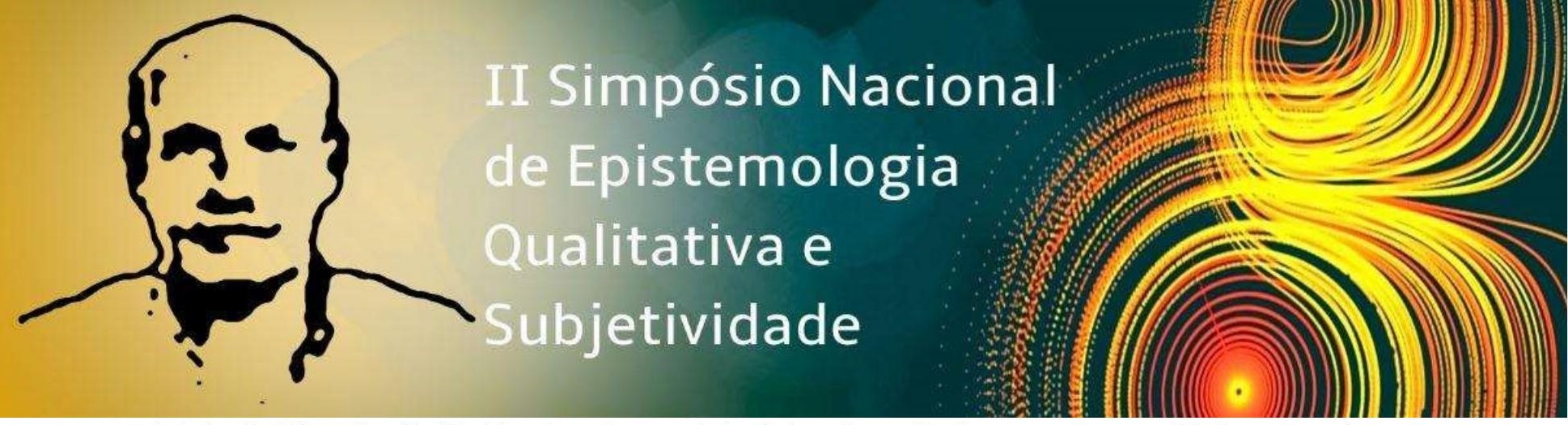

município de Pirenópolis/Goiás. A rede municipal de educação é composta por 82 docentes de educação infantil distribuídos em 9 escolas. Ressalta-se que a pesquisa envolverá um grupo de pesquisadores constituído por estudantes de graduação, pós-graduação, professores de universidades e professores da rede municipal. O referencial teórico alinha-se aos princípios da Epistemologia Qualitativa: o método construtivo-interpretativo, o processo dialógico e a singularidade como formas legítimas de produção do conhecimento. Alguns instrumentos já foram planejados, tais como: pesquisa documental, entrevistas abertas, observações participante, reuniões com grupo de docentes e formação continuada com professores. Assim, propomos a seguinte questão para reflexão: Considerando o valor heurístico da Teoria da Subjetividade em pesquisas voltadas ao estudo de políticas públicas na educação, como podemos discutir as questões epistemológicas e metodológicas nesse campo com pesquisadores iniciantes e de outras vertentes?

Palavras chave: Subjetividade. Prática docente. Políticas Públicas.

\section{Referências}

GONZÁLEZ REY, F. (2002). Sujeto y subjetividad: una aproximación Histórico Cultural, Subject and subjectivity: A cultural-historical approach. México, MX: Thomson Eds. GONZÁLEZ REY, F. (2005). Pesquisa Qualitativa e Subjetividade. Os processos de construção da informação. São Paulo: Ed. Pioneira Thomson Learning.

GONZÁLEZ REY, F. (2016). Advancing the topics of social reality, culture, and subjectivity from a cultural-historical standpoint: Moments, paths, and contradictions. Journal of Theoretical and Philosophical Psychology, 36(3), 175-189.

VELHO, C.H.M (2016). Funcionamento e Organização da Educação Infantil: elementos subjetivos de uma equipe municipal. Dissertação de mestrado. Brasil: Universidade de Brasília. Disponível em: http://repositorio.unb.br/handle/10482/20772 